\title{
A Review of Current Trend in Design for Sustainable Manufacturing
}

\author{
Negin Ashrafi \\ Department of Mechanical and Manufacturing Engineering Faculty of Engineering, University Putra Malaysia
}

\begin{abstract}
Manufacturing, as the main symbol of the civilized lifestyle, will be intensely affected by the sustainability matters and it will play a important role in establishing a sustainable way ahead. This article defines sustainable manufacturing and design for sustainability. Sustainability can be incorporated into design, including design for environment, design for resources and energy, and design for sustainability and measuring energy consumption in manufacturing. An overview of current trends and new conceptions in the evolving of sustainable products developments by presenting Life Cycle Assessment method for products and processes, and optimization techniques for sustainable manufacturing processes will be presented.
\end{abstract}

Keywords: Sustainable Manufacturing, Life Cycle Assessment, design for sustainability

\section{Introduction}

Sustainability is a fundamental matter for the present and future generations. Evolving sustainable products should be sensitive to sustainability-related standards, design, and manufacturing techniques and tools. [1] Reuse and recycling become expected requirements for product and process design. [2]

\section{I.1 Definitions of the sustainability}

One of definitions of the sustainability is Brundtland description. It explains sustainability as "meeting the needs of the present generation without compromising the ability of future generations to meet their own needs". Sustainability is the aim of sustainable improvement and this is described as "types of economic and social development that protect and enhance the natural environment and social equity'

Sustainability is a progressively important requirement for human. A technical form of this definition is as follows "Sustainable manufacturing is a systems approach for the creation and distribution (supply chain) of innovative products and services that decreases natural resources (raw materials, energy, water, and earth); reduces toxic elements; and produces less waste that in effect reduces greenhouse gases, e.g., carbon intensity" The US Department of Commerce describes sustainable manufacturing as "the creation of manufactured products that use processes that minimize negative environmental impacts, conserve energy and natural resources, are safe for employees, communities, and consumers and are economically." [3].

The Organization for Economic Co-operation and Development (OECD) explains the general principle of sustainable manufacturing "to reduce the intensity of materials use, energy consumption, emissions, and the creation of unwanted by-products while maintaining, or improving, the value of products to society and to organizations." The OECD also relates the term 'sustainable manufacturing' to 'eco-innovation'

The Australian and New Zealand Standard Industrial Classification (ANZSIC) meaning of manufacturing is "the physical or chemical transformation of materials, substances or components (being the products of agriculture, forestry, fishing and mining, or the products of other manufacturing units) into new products." [4]

\section{Main Trends In Sustainable Manufacturing}

Sustainable progress is the vision that environmental, social, economic and concerns should be considered simultaneously and holistically in the advance process. This definition contains of three main drivers: the environment, economics and society [5]. Sustainability has been applied to so many fields, including engineering; manufacturing and design [6]. Manufacturers are increasingly concerned about the issue of sustainability. Making manufacturing sustainable requires balancing and integrating economic and supportive policies and practices, environmental and social objectives. Figure1. [7]

\section{II.1The advantageous of sustainable manufacturing:}

1) Reduce the usage of material and energy resources and harmful environmental impact

2) Improve the energy efficiency by energy management systems and resource efficiency

3) Reusing and recovering energy implemented in production systems

4) Using renewable resources [8]

5) Lowest quantity of wastes 
6) Afford operational safety

7) Offer improved personal health while maintaining or improving the product and process quality. [9]

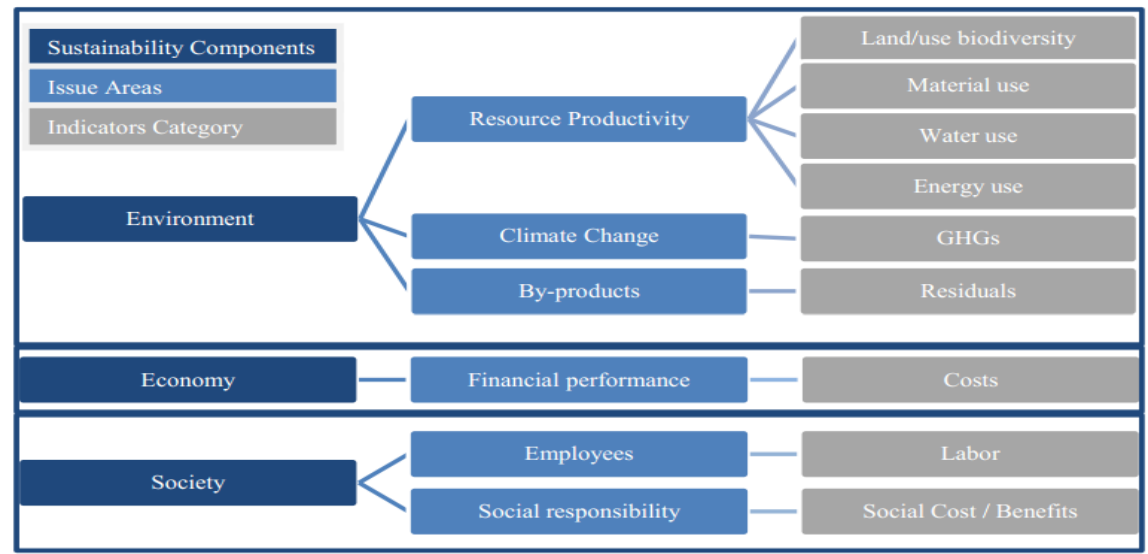

Figure1. Three levels of sustainability

\section{Background of sustainable manufacturing system}

Nowadays there is growing area for nearly each manufacturer to go "green", but what does "going green" really mean? Green manufacturing is good, but not if it delays your skill to contest in the market. If the company defined the aims and proper methods, green manufacturing grasps possible financial benefits including: long-term cost savings, waste decreases and process efficiency developments. ISO 14001, the environmental management systems (EMS) standard comprises requirements for the avoidance of pollution and for continual progress. Improving a sustainable manufacturing system increases extra factors to be controlled consecutively and this can cause problem if the decision-makers requisite to handle a multitude of diverse elements that are not integrated into the analysis of one single simulation [10]. Eco-design is one of the methods evaluating the environmental features of a product system commonly based on Life cycle assessment (LCA). Eco-design purposes to ensure that new products/services are designed to cause less environmental harm over their lifecycle. [11] .Ramani et al. studied design issues as related to sustainable product understanding, and emphasized on critical gaps preventing the integration of eco-design for sustainable manufacturing. [12]

\section{Evolution of sustainable manufacturing}

Commonly, the four steps in real practice for reducing the environmental impact of industrial production can categorized as below: First, recognize the sources of the environmental effect; second, measure the environmental impact of industrial emissions and wastes; third, detect development opportunities for reducing the environmental impact; finally, implement approaches to decrease the environmental impact and assess their efficacy Figure 2.

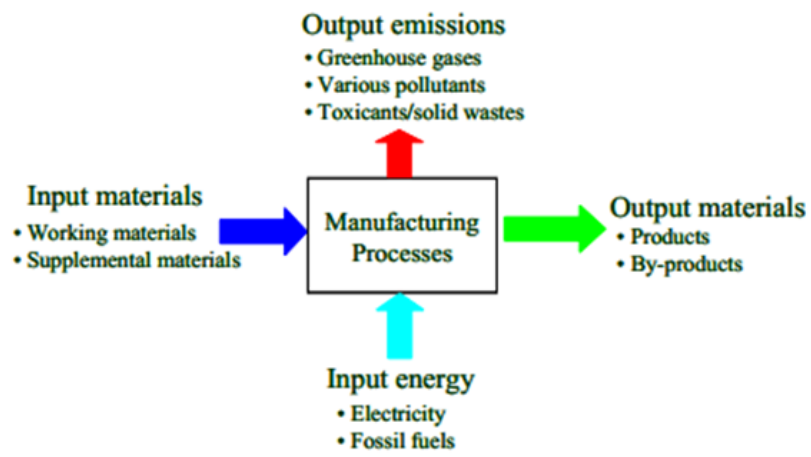

Figure 2. Manufacturing input-output structure

The diagram below, Figure 3, demonstrates the progress of sustainable manufacturing performs, signified in steps; pollution control, cleaner production, eco-efficiency, life cycle thinking, closed-loop production and industrial ecology. Manufacturing companies have focused on resolutions that employ more 
integral procedures to diminish material and energy flows by altering services products and manufacturing approaches and revitalizing willing productivity as new resources for manufacturing. [13]

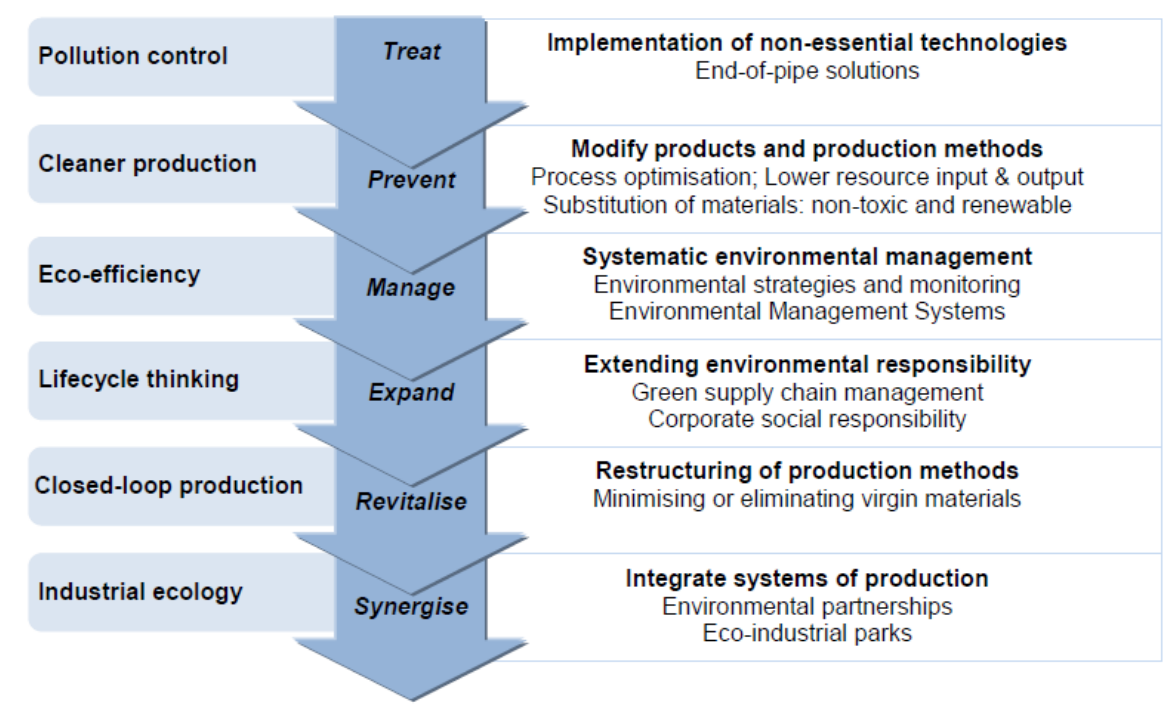

Figure 3. The evolution of sustainable manufacturing concepts and practices

\section{IV.1 Life cycle assessment}

Sustainable manufacturing approach have three significant components which are: (1) selection of practical metrics for measuring sustainable of manufacturing, (2) repeatable life-cycle assess LCA (3) optimization and improvement of the system to decrease environmental effects and expense based on the chosen the LCA and metrics. [14]

Preferably, decision to develop the environmental performance of a manufacturing process or system should be supported by LCA, as established by recent work for a number of processes, including steelmaking, die-casting, sand casting, machining, grinding, selective laser sintering, and injection molding [15]

LCA is used to prevent pollution and green design purposes. LCA is combined with the ISO series 14040 standards life cycle valuation is often used in combination with calculation of toxicity and potential of risk to foster manufacturing sustainability. [16]

LCA has emerged as one of the most common methods for evaluating environmental influence of manufactured products. As distinct in ISO 14040, LCA addresses the environmental aspects and potential environmental impacts, e.g., resource use and environmental. consequences of releases, over a product's life cycle from raw material acquisition through production (cradle to gate), use, end-of-life recovery, and disposal (cradle to grave).[17]

[18] present several review work about sustainability assessment methodologies. Singh et al. repeats some of the surveyed indices actually consider each pillar of sustainability, and most focus on a single pillar. Sala et al. also review regarding the improvement of sustainability assessment, focusing on methodology features [19]

\section{IV.1.1 Metrics}

Qualitative and quantitative metrics are essential for assessing and improving the sustainability of manufacturing systems. The final aim of evolving metrics for sustainable manufacturing is to progress decisionmaking principles when optimizing process and system designs. [20]

Hutchins et al. developed a social sustainability framework for manufacturers based on a hierarchy of social needs and social groupings; the Delphi data collection method was then employed to find metrics for each of 30 need/group categories. [21]

As mentioned before, One of the best tool for evaluating environmental effects and assisting decisionmaking over the development of new products/services and processes is LCA. Figure 4.This tool is based on goals to decrease the usage of resources and environmental impacts during the entire life-span of products and services. Lifecycle philosophy goes beyond cleaner production. [22]

For this purpose, LCA is also referred to as "cradle to grave" analysis [23].These explanations directed to the development of LCA is a methodological tool that applies life cycle thinking in an quantitative way on environmental analysis of activities related to processes or products (goods and services).A life cycle assessment consists of four steps: 1. Aim definition 2.Inventory Analysis 3.Impact Assessment 4.Improvement Assessment/Interpretation. 
Eastlick et al. described recent effort that developed a sustainable manufacturing assessment tool to quantify a comprehensive set of metrics using unit process-based modeling.[24].Lu et al. presented a structure for developing sustainable manufacturing metrics and discussed the interrelationships and potential interactions among metrics [25]

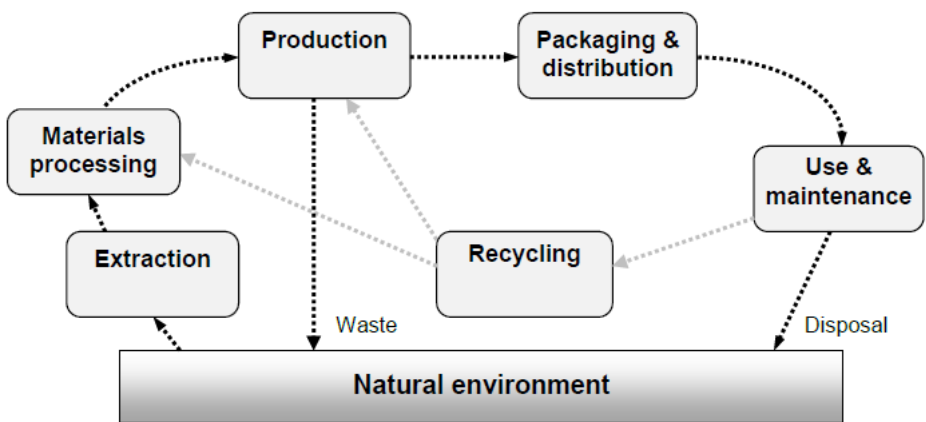

Figure 4. Life Cycle thinking

\section{IV.2 Closed-loop production}

Closed-loop production is similar to the lifecycle thinking but discriminates itself by "closing" the material resource cycle, inferring all components that currently exist in the system are reused, re-manufactured or re-sourced in some way. By definition, closed-loop supply chains aim at closing material flows, thereby limiting emission and residual waste, but also providing customer service at low cost. [26]Negative environmental impacts, such as waste, energy consumption, transport processes and packaging, can be avoided if companies establish closed-loop production systems [27]

The traditional manufacturing is concept as open-loop manufacturing. [28] Conservative open-loop product systems- raw material extraction, manufacturing products, using and then disposing them into landfills .Efforts to make manufacturing more sustainable must consider issues at all relevant levels - product, process, and system - and not just one or more of these in isolation.

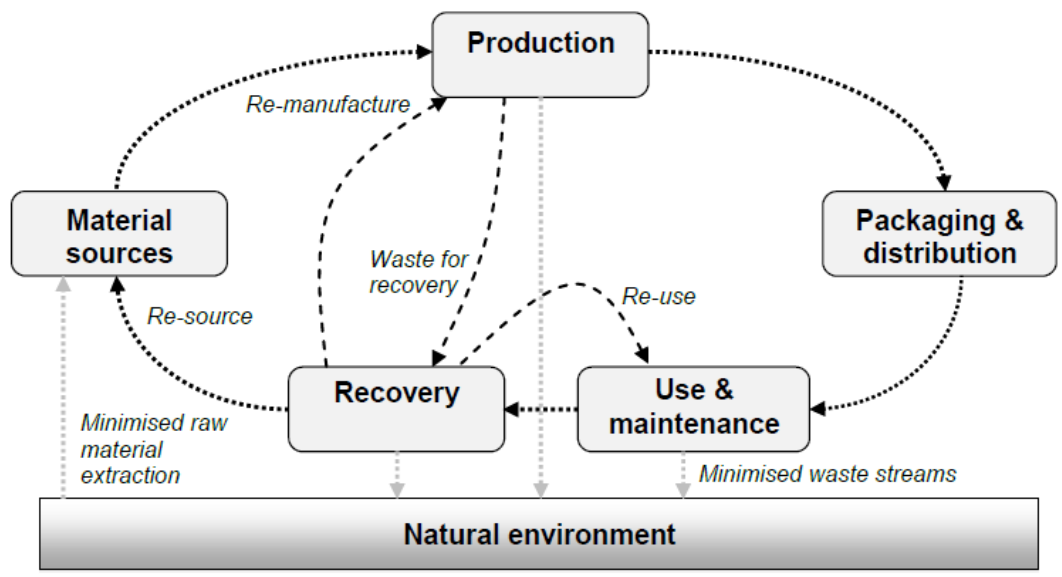

Figure 5. Closed-loop manufacturing

\section{Design and sustainability}

Design for environment contains the examination of environmental influence during the design process, and methods an essential component of designing for sustainability. To develop a comprehensive understanding of environmental influences, the full life cycle of a product or process typically desires to be considered. [14]

Sustainability can be incorporated into design, during all phases of the design process, and many tools to support such activities have been developed and applied. Some of these are described in this section, including design for environment, design for resources and energy, and design for sustainability[29].Sustainable product progress initiatives (eco-design) have been growing to support companies develop more sustainable products.[30].Designers wishing to promote sustainable manufacturing must consider factors such as time, quality, resources, and costs along with environmental performance [31] 


\section{V.1 Design for Production}

\section{V.1.1 Decreasing Resource and Energy Flows}

Good design should have a low environmental impact they should minimize the use of supplementary especially hazard materials and energy, lead to only limited losses of raw material and generate as little waste as possible.

Designers can use engineering principles to diminish the usage of resources, including:

- Outlining realistic requirements for stiffness and strength.

- Developing part dimensions, for example, using finite element analysis.

- Choosing the most suitable materials for the product life-cycle. For instance, upgrading to a tougher plastic to attain stiffness will typically need minor quantities, but may lead to increased manufacturing cost and reduced recyclability at end-of-life.

\section{V.2 Design for Green Use}

\section{V.2.1 Reducing Energy Consumption}

The most significant matters during consumption are energy and waste First energy. A comprehensive review of work conducted (over 200 publications) in the international research community in energy efficient manufacturing has been reported by Duflou et al. They offer a number of conclusions regarding the potential for significant energy efficiency gains from the machine through the supply chain level. [32]

\section{V.2.2 Reducing Waste Production}

A second step is to design the product so that the less consumable are essential for its proper operative. [37].Metal components are more costly than plastic replacements, but they are also extremely recyclable and can be reused. In some cases, plastics cannot be recycled to encounter Waste Electrical and Electronic Equipment (WEEE) directive aims; it may make increase use of metals. To decrease expenses, reverting to metal would need companies to develop their product designs to make components and sub-assemblies thinner, smaller, lighter, and to maximize opportunities for component reuse. New metal alloys are developed which may suggested extra end-of-life benefits rather than plastics.

\section{V.2.3 End-of-life Design}

A product's end-of-life system states to what happens to the product after its lifetime over. The end-oflife strategy is intended to the recycle of valuable product components and ensuring proper waste management. [33]

\section{International Regulations}

The international regulations related to environment have the role to defend the responsible societies, which, through their own strategies, are listed in the direction of sustainable development. [34]

A few key regulations warrant attention. These include:

- Registration, Evaluation, Authorization and Restriction of Chemical Substances (REACH) Regulation

- Restriction of Hazardous Substances (RoHS) Directive

- WEEE Directive[35]

Each of the above originated in the EU, they represent the basis for or have inspired similar regulations in other countries (e.g. China, Korea, and Turkey) as well as U.S states (e.g. California). [36]

\section{Conclusion}

In the real practice, the sustainable manufacturing efforts need to be adopted with a comprehensive consideration of the three components: technology, material, and energy, of a manufacturing system. New principles are essential to decrease emission and waste, and require life cycle driven approaches supported by advanced management tools such as LCA. LCA, as a systematic analysis tool, considers the environmental impact of a subject system during its whole life cycle. Research focus on sustainable manufacturing of nanotechnologies would be significant in understanding and minimizing the environmental impact of such technologies during their early development stages.

Despite so many progresses made in different engineering research, challenges and opportunities need to be addressed in following sustainable manufacturing goals. These investigations needs generally four categories: (1) manufacturing processes and equipment, (2) manufacturing systems, (3) changes in life cycle paradigms, and (4) education, new models for sustainable manufacturing education must aim to change the mindsets of future generations. Solutions that enable the substitution of toxic materials with non-toxic replacements and the decrease of material consumption should be considered. 


\section{References}

[1]. Natalia Duque, Ciceri, Marco Garetti, Severine Sperandio, From Product End-of-Life Sustainable Considerations to Design Management, Advances in Production Management Systems. New Challenges, New Approaches (2010) Volume 338, 152-159

[2]. Günther Seliger, Marwan M.K. Khraisheh, I.S. Jawahir, Advances in Sustainable Manufacturing: Proceedings of the 8Th Global Conference on Sustainable Manufacturing, Springer, 2011

[3]. Giovannini, A., Aubry, A., Panetto, H., Dassisti, M., \& El Haouzi, H. Ontology-based system for supporting manufacturing sustainability. Annual Reviews in Control, 36(2), 2012, 309-317,

[4]. J King, K. S.. Strategic innovation priorities for sustainable manufacturing in Australia, 2013, 37-42

[5]. Reich, C., Vijayaraghavan, A., Dornfeld, D., metrics for sustainable manufacturing, Proceedings of the 2008 International Manufacturing Science and Engineering Conference MSEC, 2008, 1-10.

[6]. Sudarsan Rachuri, Ram D. Sriram, Anantha Narayanan, Prabir Sarkar, Jae-Hyun Lee, Kevin W. Lyons, Sharon J. Kemmerer (Eds.), Sustainable Manufacturing: Metrics, Standards, and Infrastructure -Workshop Report, NISTIR 7683, 2010

[7]. Marc A. Rosen and Hossam A. Kishawy, Sustainable Manufacturing and Design, Concepts, Practices and Needs. 4(2), 2012, 154174

[8]. Dr. Juanjo Zulaika, trends in sustainable manufacturing, Pro-Factory Plus, 2011

[9]. I.S. Jawahir, F. Badurdeen and K.E. Rouch, Innovation in Sustainable Manufacturing Education, Institute for Sustainable Manufacturing (ISM)University of Kentucky,Lexington, KY, USA.2011

[10]. S. J. Mason, R. R. Hill, L. Mönch, O. Rose, T. Jefferson, J. W. Fowler eds., SIMULATION-BASED SUSTAINABLE MANUFACTURING SYSTEM DESIGN, Proceedings of the Simulation Conference,2008

[11]. Ilgin, M. A., and Gupta, S. M "Environmentally Conscious Manufacturing and Product Recovery (ECMPRO): A Review of the State of the Art," J. Environ. Manage., 91(3), 2010 ,563-591

[12]. Ramani, K., Ramanujan, D., Bernstein, W. Z., Zhao, F., Sutherland, J., Handwerker, C., Choi, J.-K., Kim, H., and Thurston, D. ,Integrated Sustainable Life Cycle Design: A Review, ASME J. Mech. Des., 132(9), 2010, 091004.

[13]. OECD, Business and the Environment: Policy Incentives and Corporate Responses Contributor Organization for Economic Cooperation and Development, (2007)

[14]. N. Duque Ciceri, T. G. Gutowski, M. Garetti, A Tool to Estimate Materials and Manufacturing Energy for a Product, IEEE, 2010

[15]. Kellens, K., Dewulf, W., Deprez, W., Yasa, E., and Duflou, J., "Environmental Analysis of SLM and SLS Manufacturing Processes," Proceedings of LCE2010 Conference, Hefei, PRC, 2010, 423-428

[16]. Huisman, J.: The QWERTY/EE Concept Quantifying Recyclability and Eco-Efficiency for End-of-life Treatment of Consumer Electronic Products. PhD thesis, Delft TU, The Netherlands, 2003

[17]. Curran, M. A., "Life Cycle Assessment: Principles and Practice,’U.S. Environmental Protection Agency, Cincinnati, OH. 2006

[18]. Singh, R. K., Murty, H. R., Gupta, S. K., and Dikshit, A. K., , “An Overview of Sustainability Assessment Methodologies," Ecol. Indicators, 15, $2011281-299$.

[19]. Sala, S., Farioli, F., and Zamagni, A "Progress in Sustainability Science: Lessons Learnt From Current Methodologies for Sustainability Assessment: Part 1,” Int. J. Life Cycle Assess., ePub, 2012, pp. 1-20.

[20]. Jawahir, I. S., Dillon, O. W., Rouch, K. E., Joshi, K. J., Venkatachalam, A., and Jaafar, I. H., "Total Life-Cycle Considerations in Product Design for Sustainability: A Framework for Comprehensive Evaluation," Proceedings of the 10th International Research/Expert Conference, Barcelona, Spain, pp. 1-10.2006

[21]. Hutchins, M. J., Framework, Indicators, and Techniques to Support Decision Making Related to Societal Sustainability, Ph.D. Dissertation, Michigan Technological University, Houghton, MI. 2010

[22]. Ebru sahinoglu, The analysis of global sustainable manufacturing in research, politecnico di Milano, 2011

[23]. UNEP/SET AC Life Cycle Initiative, Towards a Life Cycle Sustainability Assessment

[24]. Eastlick, D. D., Sahakian, M. V., and Haapala, K. R., 2011, "Sustainable Manufacturing Analysis for Titanium Components," Proceedings of the ASME/DETC Design for Manufacturing and the Lifecycle Conference (DFMLC), Washington, D.C., 201148854.

[25]. Lu, T., Gupta, A., Jayal, A. D., Badurdeen, F., Feng, S. C., Dillon, O. W., and Jawahir, I. S., "A Framework of Product and Process Metrics for Sustainable Manufacturing," Proceedings of the Eighth International Conference on Sustainable Manufacturing, Abu Dhabi, UAE, Nov. $201022-24$.

[26]. Krikke, Harold, et al. Design principles for closed loop supply chains.De Brito, Marisa, et al. Reverse Logistics - reveiew of case studies.ERIM Report Series Research in Management. 3 April 2008.

[27]. H. Winkler, Closed-loop production systems-A sustainable supply chain approach, CIRP Journal of Manufacturing Science and Technology. vol. 4(3) 2011, p. 243-246

[28]. Rashid, Amir; Asif, Farazee M.A.;Krajnik, Peter; Nicolescu, Cornel Mihai ， Journal of Cleaner Production, , Vol.57, p.166(12),2013

[29]. Rosen, M. a., \& Kishawy, H. a.Sustainable Manufacturing and Design: Concepts, Practices and Needs. Sustainability, 4(12), 2012, $154-174$.

[30]. Maxwell, D., \& van der Vorst, R. Developing sustainable products and services. Journal of Cleaner Production, 11(8), 2003, 883895.

[31]. Choi, J.-K., and Ramani, K., , A Systematic Methodology for Integrated Assessment of Environmentally Benign and Economically Feasible Product Design, A Quest for Sustainable Product Design, VDM Verlag, Saarbrucken, Germany. 2009

[32]. Duflou, J. R., Sutherland, J. W., Dornfeld, D., Herrmann, C., Jeswiet, J., Kara, S., Hauschild, M., and Kellens, K., 2012, “Towards Energy and Resource Efficient Manufacturing: A Processes and Systems Approach,” CIRP Ann., 61(2), 2012,587-609.

[33]. Ireneusz Zbicinski, John Stavenuiter, Barbara Kozlowska, and Hennie van de Coevering, Product Design and Life Cycle Assessment,Baltic University Press, 2007

[34]. ]Mihai, c. sustainable development policies impact on foreign direct investment, Vol. 11, No. 2(14), 2011

[35]. Blumberg, Donald. Strategic Impact of New European Union Green Law Directives on Reverse Logistics and Closed Loop Supply Chains. Reverse Logistics Association Website. 25 March 2008.

[36]. OECD, Eco-Innovation in Industry Enabling Green Growth: Enabling Green Growth, OECD Innovation Strategy 2010) 